\title{
Dyslipidaemia and dysglycaemia in HIV- infected patients on highly active anti-retroviral therapy in Kumasi Metropolis
}

\author{
*Ngala RA ${ }^{1}$, Fianko $\mathrm{K}^{2}$ \\ 1. Department of Molecular Medicine, Kwame Nkrumah University of Science \&Technology \\ 2. Department of Biochemistry, Ghana Health Service
}

\begin{abstract}
Back ground: Diet and genetic predisposition significantly affect lipid metabolism in the individual. This metabolic effect is further challenged in patients infected with HIV and on HAART. The prolonged use of HAART is associated with lipodystrophy, dyslipidemia, and insulin resistance.

Objective: To determine the prevalence of lipid dysregulation and dysglycaemia in HIV infected patients on HAART in the Kumasi metropolis.

Methods: This cross sectional study was conducted between October 2009 and June 2010, and 305 HIV-infected patients consisting of 164 patients on HAART for at least six months and 141 HAART-naive patients constituted HIV-positive patients, not on HAART and whose CD4 were not below $320 \mathrm{cell} / \mathrm{ml}$ as the control. Data was analyzed using Graph Pad Prism (version 5.0). Unpaired t-test, linear and multivariate regression analyses, was used to predict glucose level from the various parameters. Anthropometric parameters consisting of body weight, waist and hip circumferences, height, bicep and triceps skin fold were measured with a pair of calipers. Lipid profile and fasting blood glucose were determined by enzymatic methods. CD4 counts and hemoglobin were determined.

Results: Fasting plasma, glucose $(3.81 \pm 0.08 \mathrm{mmol} / 1,4.48 \pm 0.17 \mathrm{mmol} / \mathrm{l})$, total cholesterol $(3.05 \pm 0.08 \mathrm{mmol} / 1$, $4.54 \pm 0.08 \mathrm{mmol} / \mathrm{l}) \mathrm{LDL}(2.24 \pm 0.07 \mathrm{mmol} / 1,2.87 \pm 0.07 \mathrm{mmol} / \mathrm{l})$ and $\mathrm{HDL}(0.85 \pm 0.04 \mathrm{mmol} / 1,0.97 \pm 0.03 \mathrm{mmol} / \mathrm{l})$ between the control and case respectively were significantly raised $(\mathrm{P}<0.001)$, though within the physiological range. The significantly increased hip and waist circumferences, waist-to-hip ratio $(0.85 \pm 0.22,0.88 \pm 0.01)$ of the control and case correlated with lipodystrophy.

Conclusion: HAART was associated with lipodystrohy and, the risk of developing type II diabetes among the HAART experienced group was 5 times higher than the HAART naive group.

Keywords: HIV, HAART, non-nucleoside reverse transcriptase inhibitor, nucleoside reverse transcriptase inhibitor, Hypertriglyceridemia

African Health Sciences 2013; 13(4): 1107 - 1116 http://dx.doi.org/10.4314/ahs.v13i4.35
\end{abstract}

\section{Introduction}

The search for vaccines to protect against HIV/AID has continued to elude the science world. However, the use of highly active antiretroviral therapy (HAART) has dramatically improved the prognosis of HIV-infected individuals ${ }^{1,2}$. The beneficial effect of reduced risk of early death from opportunistic infections and other consequences of HIV infection, is however, reduced because other possible causes of death have replaced this beneficial effect ${ }^{3}$. Myocardial infarction has become a matter of particular concern. Two of the main sources of cardiovascular disease are believed to be vascular

* Corresponding author:
Robert Ngala
Department of Molecular Medicine
Kwame Nkrumah University of Science \&
Technology
Ghana
Email: rngala2000@yahoo.com

inflammation and dyslipidemia. Unfortunately, the use of these agents have given rise to metabolic and morphological abnormalities termed lipodystrophy syndrome and cardiovascular diseases ${ }^{4,5}$. There is sufficient evidence that lipodystrophy is linked to hypercholestrolaemia, hypertriglyceridaemia, hyperinsulinaemia, peripheral insulin resistance and even to overt diabetes ${ }^{6,7}$.

Although there are differences between the individual drugs with respect to the resulting metabolic abnormalities, treatment with protease inhibitors (PI) and to some extent nucleoside analogues such as reverse transcriptase inhibitors (NRTIs) and nonnucleoside reverse transcriptase inhibitors (NNRTIs) are known to be associated with hyperlipidaemia, hypertriglycereldaemis, lypodystrophy, hyperglycaemia and increased insulin resistance ${ }^{5,8}$ Low levels of total and high-density lipoprotein cholesterol (HDL-C) are also known to be associated with chronic HIV infection ${ }^{9}$. Although this 
dyslipidaemia has been attributed to PI therapy, dyslipidamia has also been observed in treatmentnaive HIV-infected individuals suggesting that HIV infection itself has a lipid metabolic derangement ${ }^{10,11}$.

Treatment with retonavir in healthy volunteers resulted in hypertriglyceridaemia which is not associated with impaired lipoprotein lipase activity ${ }^{9}$ and treatment with indinavir may lead to insulin resistance and lipid metabolic dysregulation ${ }^{12}$. However, the exact mechanism by which the HIV infection or HAART induces dyslipidaemiais still being researched into. Carpentier, et al. ${ }^{13}$ showed that insulin-mediated suppression of plasma free fatty acid concentrations was impaired both prior to and following introduction of HAART, compared to healthy, matched controls. VLDL-apoB and VLDLTG concentrations rose significantly from normal levels after HAART. Compared to healthy control subjects, VLDL fractional catabolic rate and clearance in HIV-seropositive individuals was reduced approximately by $40 \%$, and this defect was not corrected after HAART. The increase in VLDL after HAART was associated with an increased VLDLapoB and VLDL-TG secretion towards the normal while the impaired VLDL clearance remained unchanged.

Susceptibility to the development of these metabolic defects varies with the individual and could be influenced by genetic difference ${ }^{14}$. The recently observed association between the APOC3-related rs10892151 polymorphism and serum triglyceride levels led to the believe that genetic differences may play a major role in human immunodeficiency virus (HIV) antiretroviral therapy-induced dyslipidemia ${ }^{15}$. Although similar result have been reported in Asia, America and Europe very little work in Ghana has been done to determine the effect of HAART on lipidystrophy in HIV patients and particularly in the Ashanti region of Ghana, a population with a difference in ethnicity and dietary (from Europe and America) which may all have effect on fat and carbohydrate metabolism.

\section{Methods}

The study was carried out at Kumasi South Hospital with the permission ofthe National Aids Control Programme. All procedures were approved by the Committee on Human Research Publication and Ethics of School of Medical Sciences, KNUST (CHRPE/Student/113/09). A written informed consent form was completed by all the participants who were recruited into the study after the study was explained in a language they understand. Pretested questionnaires were used to record information of the participants. Information on demography, life style, physical examination and anthropometric measurements were taken.

\section{Study design}

A cross sectional comparative study of 305 HIVinfected patients conducted between October 2009 and June 2010. Out of this number, 164 patients were on highly active antiretroviral therapy for at least six months and above (HAART- experienced) and 141 HAART- naïve, patients constituted HIVpositive patients, not on HAART and whose CD4 was not below the critical value of $320 \mathrm{cell} / \mathrm{ml}$ ). The age range of the HAART experienced was 22 to 60 years, (mean \pm S.E.M of $38.18 \pm 0.65$ years) and that of the HAART naive, between 20 to 64 years (mean \pm S.E.M of $38.81 \pm 0.76$ years). Of the 164 HAART experienced participants, 122 (74.4\%) were females and $42(25.6 \%)$ were males, (mean \pm S.E.M of $37.33 \pm 0.77$ and $40.64 \pm 1.16$ respectively). The HAART-naïve group had 86 (61.0\%) participants being females and $55(39.0 \%)$ males (mean \pm S.E.M of $36.59 \pm 1.01$ and $42.27 \pm 1.01$ respectively).

WHO recommended antiretroviral medicines were used: Stavudine, lamivudine, Efavirenz, Zidovudine and Nevirapine. All the HAART experienced participants involved in the study used a combination of these medicines, grouped under NRTI consisting:Stavudine, lamivudine and Zidovudine and NNRTI consisting of Nevirapine and Efavirenz. The combination consisted of a Stavudine based lamivudine with either Nevirapine or Efavirenz and a Zidovudine based lamivudine combined with either Nevirapine or Efavirenz.

Participants with opportunistic infections, pregnant women and patients with known type I and II diabetes and (or) hypertension before HAART were excluded.

\section{Anthropometric measurement}

Body weights were measured (to the nearest 0.5 kilogram), with the subject standing on a weighing scale after it was adjusted to zero $\mathrm{kg}$, and calibrated using known weights. Heights were measured (to the nearest 1.0 centimeter), with the subject standing in an erect position against a vertical scale of portable standiometer and an L-square placed on the head, and the head positioned tolevel with the inferior margin of the bony orbit. The waist measurements 
were taken from the middle point between the iliac crest and the last rib, as recommended by the World Health Organization. Hip circumference was measured as the maximal circumference over the buttocks. Hip and Waist circumferences were measured twice to the nearest centimeter and the mean were used for subsequent analysis. Skin fold measurement was done with a pair of calipers (Body care CV47 OD, UK) at four standard points: subscapular (on the Back below shoulder blade), suprailiac (Side of waist), bicep and triceps skin folds. All measurements were read in centimeters $(\mathrm{cm})$ but the height was converted to meters. BMIs were then calculated as weight in kilograms divided by the height in meter squared.

\section{Sample preparation and Biochemical assay}

Fasted blood samples (overnight fast between 8-12 hours) were drawn from the median cubital vein on the anterior forearm into plain and fluoride oxalate tubes, BD vacutainer ${ }^{\circledR}$, (BD, Plymouth, PL6 7BP. UK), to prevent glycolysis.

The clotted blood was centrifuged using centrifuge (D-78532, Tuttlingen, Germany) at $2000 \mathrm{rpm}$ for 5 minutes to separate out the serum. The serum was used to estimate the lipid profile: Total cholesterol (TC), High density lipoprotein cholesterol (HDL), low density lipoprotein(LDL) and triglycerides (TRG) were estimated by direct enzymatic assay with Selectra Junior (Vital Scientific, N.V. Netherlands) automated assay. Protocol for assay by the kit manufacturer (ELITECH DIAGNOSTICS) was strictly adhered to. Interassay coefficient of variation (2.3\% and $2.1 \%$ for low and high total cholesterol controls respectively comply with National Cholesterol Education Programme recommendation ${ }^{16 .}$ The remaining serum which was not immediately used was stored at $-20^{\circ} \mathrm{C}$. Anticoagulated blood was gently mixed with blood mixer (Sarstedt, D-5223, Numbrecht, West Germany). Haemoglobin concentration was estimated with Sysmex $(\mathrm{KX}-21 \mathrm{~N})$ and Cluster of differentiation $4\left(\mathrm{CD}_{4}\right)$ was done with Becton Dickinson FACSCount ${ }^{\mathbb{B}}$ (BD Biosciences, San Jose, CA 95131 USA). The fluoridated anticoagulated blood was centrifuged (Zentrifugen, D-78532, Tuttlingen, Germany) at $3000 \mathrm{rpm}$ for 5 minutes to separate the plasma from the deposit. The plasma was used to estimate the fasting blood glucose(FBS) by enzymatic method using the automated Selectra Junior.
Normal value range of measured parameters in Kumasi Laboratory include (FBS $3.36 .4 \mathrm{mmol} / 1$ ,TC;3.1-6.5 mmol/1, TRIG 0.3-1.7mmol/1, HDL 0.75-1.88 mmol/1, LDL. 3.88-4.91 mmol/l) ${ }^{17}$ were used to determine the lower and higher parameters levels.

\section{Statistical analysis}

Data were entered into Microsoft Office Excel version 11.0 (Microsoft Corporation, USA), and further analyzed using Graph Pad Prism (version 5.0). The unpaired t-test was done for the mean $\pm \mathrm{SD}$ with the $95 \%$ confidence interval. Statistical significance was set at $\mathrm{p}$-valuesd $<0.05$ for the various parameters in the study. A linear regression and multivariate regression analyses, was done considering sex and the measures of fat distribution to find predictors of glucose level from the various parameters.

\section{Results}

Height, body weight, waist circumference, Waist-toHip ratio, bicep skin fold, systolic and diastolic blood pressure were all significantly higher $(p<0.0001)$ in the HIV-infected HAART experienced patients than the control. There were no significant differences between the subjects and the control for BMI, subscapular skinfold. A similar trend was observed for the female and male subjects in comparison to the general population. Even though these parameters were significantly higher in the subjects than the controls all these parameters were within the physiological control levels. 
Table 1: Anthropometric parameters of the Study population

\begin{tabular}{|c|c|c|c|c|c|c|c|}
\hline Variables & $\begin{array}{c}\text { Control } \\
(\mathrm{N}=86: \mathrm{F}, 55: \mathrm{M})\end{array}$ & $\begin{array}{c}\text { Case } \\
(\mathrm{N}=164)\end{array}$ & P-value & $\begin{array}{c}\text { Female cases } \\
\qquad(\mathrm{N}=122)\end{array}$ & P-value & $\begin{array}{c}\text { Male cases } \\
(\mathrm{N}=42)\end{array}$ & P-value \\
\hline Age(years) & $38.81 \pm 0.76$ & $38.18 \pm 0.65$ & 0.5290 & $37.33 \pm 0.77$ & 0.5616 & $40.64 \pm 1.16$ & 0.2914 \\
\hline Height(m) & $1.52 \pm 0.01$ & $1.60 \pm 0.01$ & $<0.0001$ & $1.57 \pm 0.01$ & $<0.0001$ & $1.67 \pm 0.02$ & $<0.0001$ \\
\hline $\mathrm{BW}(\mathrm{kg})$ & $54.87 \pm 0.90$ & $60.37 \pm 0.73$ & $<0.0001$ & $59.54 \pm 0.89$ & 0.0002 & $62.79 \pm 1.14$ & 0.0005 \\
\hline BMI(Kg/m2) & $23.98 \pm 0.44$ & $24.07 \pm 0.33$ & 0.8729 & $24.47 \pm 0.39$ & 0.8842 & $22.90 \pm 0.67$ & 0.5956 \\
\hline $\mathrm{WC}(\mathrm{cm})$ & $77.35 \pm 0.68$ & $83.77 \pm 0.67$ & $<0.0001$ & $84.25 \pm 0.82$ & $<0.0001$ & $82.40 \pm 1.08$ & 0.0050 \\
\hline $\mathrm{HC}(\mathrm{cm})$ & $91.16 \pm 0.62$ & $95.21 \pm 0.70$ & $<0.0001$ & $96.02 \pm 0.85$ & $<0.0001$ & $92.86 \pm 1.10$ & 0.2952 \\
\hline WHR & $0.85 \pm 0.00$ & $0.88 \pm 0.01$ & $<0.0001$ & $0.88 \pm 0.01$ & 0.0001 & $0.89 \pm 0.01$ & 0.0005 \\
\hline $\operatorname{Biceps}(\mathrm{mm})$ & $4.18 \pm 0.22$ & $5.78 \pm 0.24$ & $<0.0001$ & $6.25 \pm 0.29$ & 0.0002 & $4.40 \pm 0.27$ & 0.0089 \\
\hline Triceps(mm) & $8.90 \pm 0.47$ & $10.41 \pm 0.46$ & 0.0232 & $12.02 \pm 0.54$ & 0.0393 & $5.71 \pm 0.31$ & 0.1114 \\
\hline $\mathrm{SC}(\mathrm{mm})$ & $11.79 \pm 0.45$ & $12.92 \pm 0.48$ & 0.0869 & $14.24 \pm 0.56$ & 0.0399 & $9.10 \pm 0.60$ & 0.1009 \\
\hline $\mathrm{SI}(\mathrm{mm})$ & $8.57 \pm 0.34$ & $9.11 \pm 0.37$ & 0.2912 & $9.89 \pm 0.41$ & 0.2935 & $6.86 \pm 0.77$ & 0.4205 \\
\hline $\mathrm{SBP}(\mathrm{mmHg})$ & $103.62 \pm 1.26$ & $116.34 \pm 1.35$ & $<0.0001$ & $115.49 \pm 1.58$ & $<0.0001$ & $118.81 \pm 2.55$ & $<0.0001$ \\
\hline $\mathrm{DBP}(\mathrm{mmHg})$ & $67.80 \pm 0.84$ & $75.37 \pm 1.01$ & $<0.0001$ & $75.08 \pm 1.19$ & 0.0001 & $76.19 \pm 1.93$ & $<0.0001$ \\
\hline
\end{tabular}

BW: Body weight; BMI: Body mass index; WC: Waist circumference; HC: Hip circumference; WHR: Waist to hip ratio; SC: Subscapular skin fold; SI: Suprailiac skin fold; SBP: Systolic blood pressure; DBP: Diastolic blood pressure and S.E: Standard error of the mean.

Table 2: Biochemical parameters of the Study population

\begin{tabular}{|c|c|c|c|c|c|c|c|}
\hline Variables & $\begin{array}{l}\text { Control } \\
(\mathrm{N}=86: \mathrm{F}, \\
55: \mathrm{M})\end{array}$ & $\begin{array}{l}\text { Case } \\
(\mathrm{N}=164)\end{array}$ & P-value & $\begin{array}{l}\text { Female cases } \\
(\mathrm{N}=122)\end{array}$ & P-value & $\begin{array}{l}\text { Male cases } \\
(\mathrm{N}=42)\end{array}$ & P-value \\
\hline $\mathrm{Hb}(\mathrm{g} / \mathrm{dl})$ & $10.43 \pm 0.14$ & $11.77 \pm 0.12$ & $<0.0001$ & $11.69 \pm 0.14$ & $<0.0001$ & $12.01 \pm 0.22$ & $<0.0001$ \\
\hline CD4(cells/ul) & $233.35 \pm 16.69$ & $358.71 \pm 17.29$ & $<0.0001$ & $370.85 \pm 20.89$ & 0.0005 & $323.45 \pm 29.29$ & 0.0003 \\
\hline $\mathrm{FBS}(\mathrm{mmol} / \mathrm{l})$ & $3.81 \pm 0.08$ & $4.48 \pm 0.17$ & 0.0005 & $4.59 \pm 0.21$ & 0.0015 & $4.16 \pm 0.24$ & 0.1904 \\
\hline $\mathrm{TC}(\mathrm{mmol} / \mathrm{l})$ & $3.65 \pm 0.08$ & $4.54 \pm 0.08$ & $<0.0001$ & $4.69 \pm 0.09$ & $<0.0001$ & $4.09 \pm 0.15$ & 0.0015 \\
\hline TRIG(mmol/l) & $1.37 \pm 0.07$ & $1.37 \pm 0.07$ & 0.9967 & $1.38 \pm 0.08$ & 0.8093 & $1.34 \pm 0.13$ & 0.7174 \\
\hline HDL-C(mmol/l) & $0.85 \pm 0.04$ & $0.97 \pm 0.03$ & 0.0122 & $1.01 \pm 0.04$ & 0.1645 & $0.86 \pm 0.06$ & 0.0962 \\
\hline $\mathrm{LDL}-\mathrm{C}(\mathrm{mmol} / \mathrm{l})$ & $2.24 \pm 0.07$ & $2.87 \pm 0.07$ & $<0.0001$ & $2.98 \pm 0.09$ & $<0.0001$ & $2.53 \pm 0.09$ & 0.0086 \\
\hline
\end{tabular}

Hb: Hemoglobin concentration; CD4: Cluster of differentiation 4; FBS: Fasting blood glucose TC: Total Cholesterol; TRG: Triglycerides; HDL-C: High density lipoprotein cholesterol; LDL-C: Low density lipoprotein cholesterol

CD4 count, FBS, Total cholesterol, HDL and LDL were significantly $(\mathrm{p}<0.0001)$ elevated in HIV-infected HAART experienced patients. However, there was no significant change in the triglycerides levels between the control population and the subject population. A similar trend was observed for the female and male subjects in comparison to the general population. Even though these parameters were significantly higher in the subject than the controls all these parameters were within the physiological control levels except for the CD4 count. 
Table 3: Effect of HAART combination and gender on lipodystrophy

\begin{tabular}{|c|c|c|c|c|c|c|c|c|c|}
\hline \multirow[t]{2}{*}{ Fat distribution } & \multicolumn{2}{|c|}{$\begin{array}{l}\mathrm{d} 4 \mathrm{~T} / 3 \mathrm{TC} / \mathrm{NVP} \\
(\mathrm{n}=68)\end{array}$} & \multicolumn{2}{|c|}{$\begin{array}{l}\text { d4T/3TC/EFV } \\
(n=30)\end{array}$} & \multicolumn{2}{|c|}{$\begin{array}{l}\text { AZT/3TC/NVP } \\
(\mathrm{n}=36)\end{array}$} & \multicolumn{2}{|c|}{$\begin{array}{l}\text { AZT/3TC/EFV } \\
(n=21)\end{array}$} & \multirow[t]{2}{*}{ Total } \\
\hline & $\mathrm{F}$ & M & $\mathrm{F}$ & M & $\mathrm{F}$ & M & $\mathrm{F}$ & M & \\
\hline \multicolumn{10}{|l|}{ Lipoatrophy } \\
\hline Face & 17 & 1 & 5 & 6 & 3 & 3 & 2 & 2 & 39 \\
\hline Limbs & 5 & 2 & 4 & 1 & 4 & 2 & 0 & 0 & 18 \\
\hline \multicolumn{10}{|l|}{ Lipohypertrophy } \\
\hline Neck & 19 & 5 & 7 & 3 & 14 & 2 & 1 & 1 & 52 \\
\hline Breast & 12 & 1 & 2 & 0 & 10 & 2 & 0 & 0 & 27 \\
\hline Abdomen & 13 & 5 & 8 & 2 & 7 & 5 & 7 & 1 & 48 \\
\hline Buttocks & 8 & 3 & 3 & 1 & 5 & 2 & 0 & 0 & 22 \\
\hline
\end{tabular}

F: Female, M: Male

Table3.Shows fat distribution, in association with HAART used and gender across the study population

24\% HAART experienced participants had facial fat depletion. Of this figure, 18 were using $\mathrm{d} 4 \mathrm{~T} / 3 \mathrm{TC} /$ NVP combination therapy, 11, 6 and 4 were using $\mathrm{d} 4 \mathrm{~T} / 3 \mathrm{TC} / \mathrm{EFV}, \mathrm{AZT} / 3 \mathrm{TC} / \mathrm{NVP}$ and AZT/3TC/ EFV respectively. Participants on AZT/3TC/EFV combination therapy had no changes in appearance in terms of fat depletion on the limbs as well as fat accumulation in the breast and buttocks. 18, 10,12, 8 had truncal obesity after using $\mathrm{d} 4 \mathrm{~T} / 3 \mathrm{TC} / \mathrm{NVP}$, $\mathrm{d} 4 \mathrm{~T} / 3 \mathrm{TC} / \mathrm{EFV}, \mathrm{AZT} / 3 \mathrm{TC} / \mathrm{NVP}$ and AZT/3TC/ EFV combination therapy respectively.

When the result of fasting glucose was compared to duration of antiretroviral therapy (table 4.), $4.3 \%$ HAART experienced participants developed type II diabetes between 6-18 months on the therapy. Also, $0.6 \%$ and $1.8 \%$ HAART experienced participants developed type II diabetes between19-31 and after 31 months on therapy respectively. Of the 4.3\% HAART experienced participants who developed IFG, 1.2\% developed IFG between 6-18 months. 2.4\% developed IFG between 19-31 months and 0.6\% developed IFG after 31 months on therapy (table 4).

Family history of hypertension and type II diabetes are important risk factors of cardiovascular disease and diabetes. In this study, participants with a family history of type II diabetes had 7 times the chance of developing type II diabetes among the HAART experienced group: $\mathrm{X}^{2}(\mathrm{P})$, 8.6(0.0034).

Further analysis of the data suggest that HAART experienced subjects were 5 times more likely to develop type 2 diabetes, and raised CD4 count, four times likely to develop hypercholesterolemia and a significantly reduced chances of raised HDL and LDL, and a nonsignificanttriglyceride change (table 5).

Table 4: Duration of HAART in association with the development of dysglycaemia

\begin{tabular}{|c|c|c|c|c|c|c|c|c|c|}
\hline \multirow{2}{*}{$\begin{array}{l}\text { Duration } \\
\text { (Months) }\end{array}$} & \multicolumn{3}{|c|}{ Normal } & \multicolumn{3}{|l|}{ IFG } & \multicolumn{3}{|c|}{ Diabetes } \\
\hline & Total & Female & $\overline{\text { Male }}$ & Total & Female & Male & Total & Female & Male \\
\hline $6-18$ & 98 & 67 & 31 & 2 & 2 & 0 & 7 & 5 & 2 \\
\hline $19-31$ & 30 & 26 & 4 & 4 & 4 & 0 & 1 & 1 & 0 \\
\hline $31+$ & 18 & 13 & 5 & 1 & 1 & 0 & 3 & 3 & 0 \\
\hline Total & 146 & 106 & 40 & 7 & 7 & 0 & 11 & 9 & 2 \\
\hline
\end{tabular}

IFG: impaired fasting glucose; Duration: Duration of HAART in months 
Table 5: Assessment of biochemical parameters as risk factors of development of diabetes and CVD

\begin{tabular}{lllllll}
\hline Parameters & & Control & Case & OR(95\% CI) & Chi $^{2}$ & P-Value \\
\hline FBS(mmol/l) & Low & $83(58.9)$ & $86(52.4)$ & $0.9(0.6-1.5)$ & 0.08 & 0.7780 \\
& *Normal & $55(39.0)$ & $61(37.2)$ & 1 & & \\
& High & $3(2.1)$ & $17(10.4)$ & $5.1(1.3-28.4)$ & 7.33 & 0.0068 \\
TC(mmol/l) & Low & $45(31.9)$ & $15(9.2)$ & $0.2(0.1-0.4)$ & 23.68 & 0.0000 \\
& *Normal & $95(76.4)$ & $143(87.2)$ & 1 & & \\
& High & $1(0.7)$ & $6(3.7)$ & $4.0(0.5-185.2)$ & 1.87 & 0.1710 \\
TRIG(mmol/l) $)$ & Low & $0(0)$ & $1(0.6)$ & ------ & 0.87 & 0.3502 \\
& *Normal & $113(80.1)$ & $129(78.7)$ & 1 & & \\
& High & $28(19.9)$ & $34(20.7)$ & $1.1(0.6-1.9)$ & 0.05 & 0.8290 \\
HDLC(mmol/l) & Low & $84(59.6)$ & $71(43.3)$ & $0.4(0.3-0.8)$ & 10.44 & 0.0012 \\
& $*$ Normal & $48(34.0)$ & $88(53.7)$ & 1 & & \\
& High & $9(6.4)$ & $5(3.1)$ & $0.3(0.1-1.1)$ & 4.53 & 0.0333 \\
LDLC(mmol/l) $)$ & Low & $138(97.9)$ & $143(87.2)$ & $0.1(0.0-0.6)$ & 8.98 & 0.0027 \\
& *Normal & $2(1.4)$ & $15(9.2)$ & 1 & & \\
& High & $1(0.7)$ & $6(3.7)$ & $0.8(0.0-55.0)$ & 0.03 & 0.8652 \\
& $*$ Low & $52(36.9)$ & $18(11.0)$ & 1 & & \\
& Normal & $89(63.1)$ & $146(89.0)$ & $4.7(2.5-9.1)$ & 28.77 & 0.0000 \\
\hline
\end{tabular}

FBS: Fasting blood glucose; TC: Total cholesterol; TRIG: Triglycerides; HDLC: High density lipoprotein cholesterol; LDLC: Low density lipoprotein cholesterol; $\mathrm{CD}_{4}$ : Cluster of differentiation 4. OR; Odd Ratio (crude), CI, Confidence Interval.

Table 5 presents the analysis for co morbidity for type II diabetes and CVD. Total cholesterol was higher in the cases than the control and the difference was statistically significant $(\mathrm{P}=0.0068)$. Also, LDL in the cases were nonsignificantly higher than in the controls $(\mathrm{P}=0.8652)$

Table 6: Assessment of family history as risk factor of development of diabetes and CVD

\begin{tabular}{lllllll}
\hline Parameters & & Control & Case & OR(95\% CI $)$ & Chi $^{2}$ & $\begin{array}{l}\text { P- } \\
\text { Value }\end{array}$ \\
\hline FH Diabetes & $*$ No & $139(98.6)$ & $149(90.9)$ & 1 & & \\
& yes & $2(1.4)$ & $15(9.2)$ & $7.0(1.6-63.8)$ & 8.60 & 0.0034 \\
FH & $*$ No & $136(96.5)$ & $146(89.0)$ & 1 & & \\
Hypertensio & yes & $5(3.6)$ & $18(11.0)$ & $3.4(1.2-11.8)$ & 6.00 & 0.0143 \\
$\mathrm{n}$ & & & & & & \\
\hline
\end{tabular}

FH: Family history, OR: Odd Ratio

\section{Discussion}

The use of HAART has significantly decreased morbidity and mortality in HIV infected patients leading to an increase in life expectancy. However, the benefits of antiretroviral combination therapy are associated with a wide spectrum of side effects with some clinical manifestations ${ }^{18,19}$. Lipodystrophy, hyperlipidaemias, insulin resistance, hyperglycaemia and even overt diabetes has been reported in subjects treated with protease inhibitors (PIs) and nucleoside- reverse transcriptases inhibitors (NRTIs) ${ }^{20}$ Aclassification of morphological and metabolic abnormalities following HAART administration is summarized in Table.1.Suprailiac skinfold and BMI were not significantly changed between the subject and control. BMI has been shown in several studies not to give a good reflection of body fat distribution but fat to muscle mass ratio (obesity) ${ }^{21}$. Indeed waist circumference, hip circumference and hip-to-waist 
ratios which have been shown to be better reflectors of body fat distribution, were significantly elevated in the HIV-infected patients on HAART. Dyslipidaemia in the HIV-infected, is characterized by hypertriglyceridaemia, and low HDL levels ${ }^{22}$. This is mostly attributed HAART treatment. The prolonged surge of pro inflammatory cytokines such as TNF-alpha, IL-1, IL-6 IFN-alpha observed following the chronic state of HIV infection have been shown to contribute to lipid dysrgulation ${ }^{23}$. Cytokines such as TNF-alpha, IL-1, IL-6 IFN-alpha have also been reported to increase lipogenesis, decrease clearance of circulating LDL and inhibit hepatic lipase activity ${ }^{24,25}$. This probably partly account for the observed slightly increase in serum LDL levels in this study.

Dyslipidaemia has also been observed in HAART-naive HIV-infected patients, suggesting that HIV-infection itself has a metabolic deleterious effect ${ }^{10,11 .}$ It is not however certain whether these complications are exclusively due to the viral load or associated with HAART recommended by the $\mathrm{WHO}^{5,26}$. The changes in the lipid profile in this study were similar in the male and female cases suggesting that the fat distribution were not exclusively due to gender effect ${ }^{27}$. In several studies in Ghana, women have been shown to have higher waist circumference, hip circumference and hip-to-waist ratios $^{28}$ as opposed to what is typically reported in the Western World. It therefore implies that HAART is the main cause of lipid redistribution in this study since these anthropometric parameters were raised in both male and female alike. HIV-infected patients did not show dyslipidaemia despite having been on HAART for well over six months (table 2). Lipid changes were all within the physiological range. However, Total cholesterol, HDL and LDL were significantly $(p<0.0001)$ elevated in the HAART-experienced patients while triglycerides were not significantly changed. The elevated HDL contradictsthe effect of NRTI treatment which has been shown to lower HDL levels ${ }^{10,11,19}$.

Hence combination treatment with NNRTI and NRTI drugs may therefore be more beneficial than treatment with only one of the nucleosides, because elevated HDL has a positive effect in lipid metabolism as it increases reverse cholesterol transport effect and therefore anti-atherogenic and possibly partly accounting for the observed physiological level of the lipids. It is also possible that this observation could be explained by genetic influence and or the low diet fat in the Ghanaianas compared to the fat rich western diet, or due to the dietary restriction as part of treatment package. Indeed, HIV-infected patients require aggressive treatment including low-fat diets, avoidance of simple sugars, and elimination of alcohol intake ${ }^{29}$. The advert effect of high fat diet on health and fat distribution has been extensively studied ${ }^{30,31}$. Lipodystrophy characterized by peripheral loss of fat tissue and abnormal fat distribution including the enlargement of dorsocervical fatpad, lipomatosis, breast hypertrophy, and visceral abdominal fat accumulation have recently been reported in HIV-1 patients receiving HAART ${ }^{6,32-3540 .}$ In this study the combined use of NNRTI and NRTI resulted in 24\% of the subjects experiencing facial fat depletion. However, participants on AZT/3TC/EFV combination therapy had no changes in appearance in terms of fat depletion on the limbs as well as fat accumulation in the breast and buttocks. About 29\% had truncal obesity after using the various combinations of NRTI and NNRTI (table 3). The association between visceral obesity and NRTI therapy has been reported in several studies ${ }^{32,43}$.

The development of diabetes and or insulin resistance is not only due to hyperlipidaemia but also lipodystrophy ${ }^{5,8}$. Indeed increased visceral fat has been shown to be associated with the development of type 2 diabetes whilst peripheral and subcutaneous fat levels, inversely correlates to the development of type 2 diabetes. Haffner, et al. ${ }^{36}$ found that WHR was a better single screening measure for NIDDM than BMI and that upper body adiposity predicted diabetes even in leanmen and women. Ohlson,et al. ${ }^{37}$ also found that WHR was positively and significantly associated with NIDDM even after BMI was considered among men.

Metabolic syndrome has been reported in HIV patients on HAART ${ }^{38}$. Hyperglycemia, and insulin resistancethe hallmark of metabolic syndrome mostly associated with HIV patients receiving protease inhibitors, have been implicated in patients on NRTIs alone ${ }^{39}$. The development of insulin resistance and diabetes with HAART is time dependent. In this study 4.3\% HAART experienced participants developed type II diabetes between 618 months on therapy and 6.1\% between $19-31$ and after 31 months, whilst $1.2 \%$ of the $4.3 \%$ developed IFG between 6-18 months. 3.0\% developed IFG between 19-31 months and after 31 months on therapy (table 4). Several mechanisms have been proposed to explain this phenomenon. Among these, the animal and human models of diabetes 
mellitus suggest that mitochondrial dysfunction is significantly related to the development of insulin resistance. Several studies have also shown that Nucleoside reverse transcriptase inhibitors (NRTIs) impair mitochondrial function in individuals infected with human immunodeficiency virus (HIV) ${ }^{41} 42$

Even though the fasting blood glucose was significantly higher in the subjects, the significance of the difference between the HAART-experienced and HAART-naive groups as well as among the subgroups, was lost when the data was subjected to further statistical analyses to determine if this significance could correlate to the development of type 2 diabetes $\mathrm{X}^{2}(\mathrm{P})$ : 0.4(0.7904) X2(P): 3.1(0.2136). However, the risk of developing type II diabetes among the HAART experienced group was 5 times higher than the HAART naive group: $\mathrm{X}^{2}(\mathrm{P})$, 7.3(0.0068) (table 5).

The distribution of fat also shows a tendency to the development of hypertension. Even though the systolic and diastolic blood pressures in both HAART-naïve and HAART- experience subjects were within the physiological range, the levels in the HAART-experienced were significantly elevated (table1).

Family history of hypertension and type II diabetes are important risk factors for the development of these diseases. In the study, the HAART experienced group,with a family history of type II diabetes were 7 times more likely to develop type II diabetes than the HAART -naive: data not shown (table 6).

\section{Conclusion}

Waist circumference, hip circumference and waistto-hip ratio which are the key indices for assessing body fat distribution were significantly raised in HAART-experienced than HAART-naïve HIVinfected patients in Kumasi, implying that HAART could result to lipodystrophy. Even though the quantitative values of triglycerides, high density lipoprotein, low density lipoprotein and total cholesterol were all within the physiological range, total cholesterol, low density lipoproteins and high density lipoproteins were significantly raised $(\mathrm{p}<0.0001)$ in the HAART-experienced. The raised HDL level as a result of the combined use of NRTI's and NNRTI's in this study may therefore serve to improve reverse cholesterol transport and therefore bringing the lipoproteins to the physiological level and their use would be much recommendable.Also, though the fasting blood glucose levels were not significantly different between the control and the subjects, the tendency for the HAART patients to develop dysglycaemia was 5 times higher than the HAART-naive group.

\section{References}

1. Battegay M, Elzi L. Morbidity and mortality in HIV-infected individuals - a shift towards comorbidities. Swiss Med Wkly, 2009; 139(3940): 564-70.

2. da Silva E, Barbaro G. New option in treatment of lipid disorders in HIV infected patients Open Aids J 2009; 3: 31-37.

3. Calza L, Manfredi R, Chiodi F. Insulin Resistance and Diabetes Mellitus in HIV-Infected Patients Receiving Antiretroviral Therapy. Journal of antimicrobial chemotherapy 2004; 53: 10-14.

4. Farrugia PM, Lucariello R, Coppola JT. Human immunodeficiency virus and atherosclerosis. Cardiol Rev, 2009; 17(5): 211-5.

5. Nolan D, Mallal S. The role of nucleoside reverse transcriptase inhibitors in the fat redistribution syndrome. J HIV Ther. 2004; 9:34-40.

6. Miller KK Daly PA, Sentochnik D, Doweiko J, Samore M, Basgoz NO, Grinspoon SK. Pseudo-Cushing's syndrome in human immunodeficiency virus-infected patients. Clin Infect Dis 1998; 27(1): 68-72.

7. Carr A, Samaras K, Burton S, Law M, Freund J, Chisholm DJ, Cooper DA. A syndrome of peripheral lipodystrophy, hyperlipidaemia and insulin resistance in patients receiving HIV protease inhibitors. AIDS 1998; 12(7): F51-8.

18. Dube MP, Stein JH, Aberg JA, Fichtenbaum CJ, Gerber JG, Tashima KT, Henry WK, Currier JS, et al. Guidelines for the evaluation and management of dyslipidemia in human immunodeficiency virus (HIV)-infected adults receiving antiretroviral therapy: recommendations of the HIV Medical Association of the Infectious Disease Society of America and the Adult AIDS Clinical Trials Group. Clin Infect Dis 2003; 37(5): 613-27.

9. Baker J, Ayenew W, Quick H, Hullsiek KH, Tracy R, Henry K, Duprez D, JameNeaton, JD. High-density lipoprotein particles and markers of inflammation and thrombotic activity in patients with untreated HIV infection. J Infect Dis 2010; 201(2): 285-92. 
10. Fisher SD, Miller TL, Lipshultz S.E. Impact of HIV and highly active antiretroviral therapy on leukocyte adhesion molecules, arterial inflammation, dyslipidemia, and atherosclerosis. Atherosclerosis 2006; 185(1): 1-11.

11. Umpleby AM, Da S, Stolinski M, ShojaeeMoradie F, Jackson NC, Jefferson W, Crabtree $\mathrm{N}$, Nightingale $\mathrm{P}$, et al. Low density lipoprotein apolipoprotein B metabolism in treatment-naive HIV patients and patients on antiretroviral therapy. Antivir Ther 2005; 10(5): 663-70.

12. Noor MA, Seneviratne T, Aweeka FT, Lo JC, Schwarz JM, Mulligan K, Schambelan M, Grunfeld C. Indinavir acutely inhibits insulinstimulated glucose disposal in humans: a randomized, placebo-controlled study. AIDS 2002; 16(5): F1-8.

13. Carpentier A, Patterson BW, Uffelman KD, Salit I, Lewis GF. Mechanism of highly active anti-retroviral therapy-induced hyperlipidemia in HIV-infected individuals. Atherosclerosis 2005; 178(1): 165-72.

14. Bonnet E, Genoux A, Bernard J, Fauvel J, Massip P, Perret B. Impact of genetic polymorphisms on the risk of lipid disorders in patients on anti-HIV therapy. Clin Chem Lab Med, 2007; 45(7): 815-21.

15. Aragones G, Alonso-Villaverde C, Pardo-Reche P, Rull A, Beltrán-Debón R, et al. Antiretroviral treatment-induced dyslipidemia in HIV-infected patients is influenced by the APOC3-related rs10892151 polymorphism. BMC Med Genet 2011; 12: 120.

16. National Heart Lung and Blood Institute, Current status of blood cholesterol measurement in clinical laboratories in the United States: a report from the Laboratory Standardization Panel of the National Cholesterol Education Program. Clin Chem, 1988; 34(1): 193-201.

17. Eghan BA. Jr, Acheampong JW. Dyslipidemia in Outpatients at General Hospital in Kumasi, Ghana: Cross-sectional StudyCroat Med J 2003; 44:576-578

18. Barbaro G. Metabolic and cardiovascular complications of highly active antiretroviral therapy for HIV infection. Curr HIV Res, 2006. 4(1): 79-85.

19. Leclercq P, Blanc M. Metabolic abnormalities, lipodystrophy and cardiovascular risk in HIVinfected patients. Rev Prat, 2006; 56(9): 987-94.
20. Scordo KA. Treating antiretroviral-induced dyslipidemia in HIV-infected adults. Nurse Pract, 2010; 35(7): 32-7.

21. Bertoli A, Daniele ND, Ceccobelli M, Ficara A, Girasoli C, Lorenzo AD. Lipid profile, BMI, body fat distribution and aerobic fitness in men with metabolic syndrome. Acta Diabetol 2003; 40(Suppl 1): S130-3.

22. Ramezani A, Mohraz M, Yadegarinia D, Banifazl M, Gachkar L, Jam S, Aghakhani A, Eslamifar A. Prevalence of Dyslipidemia and Metabolic Abnormalities in HIV-Infected Patients. Acta Medica Iranica 2009; 47(2): 83-88.

23. Johnson JA, Albu JB, Engelson ES, Fried SK, Inada Y, Ionescu G, Kotler DP. Increased systemic and adipose tissue cytokines in patients with HIV-associated lipodystrophy. Am J Physiol Endocrinol Metab 2004; 286(2): E261-71.

24. Feingold KR, Soued M, Adi S, Staprans I, Neese R, Shigenaga J, Moser A, Dinarello CA, Grunfeld C et al. Effect of interleukin-1 on lipid metabolism in the rat. Similarities to and differences from tumor necrosis factor. Arterioscler Thromb 1991; 11(3): 495-500.

25. Nonogaki K, Fuller GM, Fuentes N L, Moser A H, Staprans I, Grunfeld C, Feingold K. Interluking-6 stimulates triglycerides secretion in rats Endocrinology 1995; 136: 2143-2149

26. Carr A, Samaras K, Thorisdottir A, Kaufmann GR, Chisholm DJ, Cooper DA. Diagnosis, prediction, and natural course of HIV-1 protease-inhibitor-associated lipodystrophy, hyperlipidaemia, and diabetes mellitus: a cohort study. Lancet 1999; 353(9170): 2093-9.

27. Xuewen W, Faidon M, Bettina M. Sex Differences in Lipid and Lipoprotein Metabolism:It's Not Just about Sex Hormones. J ClinEndocrinolMetab 2011; 96: 885-893.

28. Addo J, Smeeth L, Leon DA Obesity in urban civil servants in Ghana: association with pre-adult wealth and adult socio-economic status. Public Health 2009; 123(5): 365-70.

29. Green ML. Evaluation and management of dyslipidemia in patients with HIV infection. $J$ Gen Intern Med 2002; 17(10): 797-810.

30. Chan JM, Rimm EB, Colditz GA, Stampfer MJ, Willett WC. Obesity, fat distribution, and weight gain as risk factors for clinical diabetes in men. Diabetes Care 1994; 17(9): 961-9.

31. Mensink R.P, M.B. Katan, Effect of dietary trans fatty acids on high-density and low-density 
lipoprotein cholesterol levels in healthy subjects. N Engl J Med, 1990; 323(7): 439-45.32.

32. Pujari SN, Dravid A, Naik, E, Bhagat, S, Tash, K, Nadler JP, Sinnott J T. Lipodystrophy and Dyslipidemia Among Patients Taking First-Line, World Health Organization-Recommended Highly Active Antiretroviral Therapy Regimens in Western India J Acquir Immune Defic Syndr ;2005; 39:199-202

33. Viraben R, Aquilina C. Indinavir-associated lipodystrophy. AIDS 1998; 12: F37-39.

34. Lo JC, Mulligan K, Tai VW, Algren H, Schambelan M. Buffalo hump" in men with HIV-1 infection. Lancet 1998; 351(9106): 86770.

35. Heath KV, Hogg RS, Chan KJ, et al. Lipodystrophy associated morphological, cholesterol and triglyceride abnormalities in population based HIV/AIDS treatment base. AIDS. 2001;15:231-240

36. Haffner SM, Mitchell BD, Stern MP, Hazuda HP, Patterson JK. Public health significance of upper body adiposity for non-insulin dependent diabetes mellitus in Mexican Americans.Int J Obes Relat Metab Disord,. 1992; 16(3): 177-84.

37. Ohlson LO, Larsson B, Svärdsudd K, Welin L, Eriksson H, Wilhelmsen L, Björntorp P, Tibblin G. The influence of body fat distribution on the incidence of diabetes mellitus. 13.5 years of follow-up of the participants in the study of men born in 1913. Diabetes 1985; 34(10): 10558.

38. Samaras K, Wand H, Law M, Emery S, Cooper, D, Carr A. Prevalence of Metabolic Syndrome in HIVInfected Patients Receiving Highly Active Antiretroviral Therapy Using International Diabetes Foundation and Adult Treatment Panel III Criteria Diabetes Care. 2007; 30(1): 113-119
39. Fleischman A, Johnsen S, Systrom DM, Hrovat M, Farrar CT, Frontera W, Fitch K, et al. Effects of a nucleoside reverse transcriptase inhibitor, stavudine, on glucose disposal and mitochondrial function in muscle of healthy adults. American Journal of Physiology - Endocrinology and Metabolism. 2007; 292. E1666-E1673

40. Saint-Marc T, Partisani M, Poizot-Martin I, Bruno F, Rouviere O, Lang JM, Gastaut JA; Touraine JL A syndrome of peripheral fat wasting (lipodystrophy) in patients receiving long-term nucleoside analogue therapy AIDS 1999; 13(13): 1659-1667

41. Luzi L, Perseghin G, Tambussi G, Meneghini E, Scifo P, Pagliato E, Del Maschio A, Testolin G, Lazzarin A. Intramyocellular lipid accumulation and reduced whole body lipid oxidation in HIV lipodystrophy. Am JPhysiol Endocrinol Metab 2003; 284: E274-E280.

42. Walker UA, Bickel M, Lutke Volksbeck SI, Ketelsen UP, Schofer H, Setzer B, Venhoff N, Rickerts V, Staszewski S. Evidence of nucleoside analogue reverse transcriptase inhibitorassociated genetic and structural defects of mitochondria in adipose tissue of HIV-infected patients. JAcquir Immune Defic Syndr 2002; 29: 117-121.

43. Mulligan K, Tai VW, Algren H, Abrams DI, Leiser RJ, Lo J C, Schambelan, M. Altered Fat Distribution in HIV-Positive Men on Nucleoside Analog Reverse Transcriptase Inhibitor Therapy (JAIDS) Journal of Acquired Immune Deficiency Syndromes 2001; 26 :443-448 